\title{
Editorial
}

\section{Recent Advances in Gestational Diabetes Mellitus}

\author{
Katrien Benhalima
}

Citation: Benhalima, K. Recent Advances in Gestational Diabetes Mellitus. J. Clin. Med. 2021, 10, 2202. https://doi.org/10.3390/jcm10102202

Received: 6 May 2021

Accepted: 11 May 2021

Published: 19 May 2021

Publisher's Note: MDPI stays neutral with regard to jurisdictional claims in published maps and institutional affiliations.

Copyright: (C) 2021 by the author. Licensee MDPI, Basel, Switzerland. This article is an open access article distributed under the terms and conditions of the Creative Commons Attribution (CC BY) license (https:// creativecommons.org/licenses/by/ $4.0 /)$.
Department of Endocrinology, University Hospital Gasthuisberg, KU Leuven, Herestraat 49, 3000 Leuven, Belgium; katrien.benhalima@uzleuven.be

The incidence of gestational diabetes mellitus (GDM) and overt diabetes in pregnancy is rising globally. GDM leads to increased risks for maternal and neonatal adverse pregnancy outcomes. In addition, GDM is also associated with an increased long-term metabolic risk in mothers and offspring [1]. Although much is known about GDM, evidence gaps persist. For instance, more research is needed on how to prevent GDM, on whether screening and treatment of GDM in early pregnancy are beneficial, on non-fasting biomarkers to screen for GDM, on new biomarkers to predict pregnancy complications, and on how to reduce the long-term metabolic risk in mothers and infants after delivery. To address this important health issue, the present Special Issue in the Journal of Clinical Medicine was dedicated to recent advances in the field of GDM. This Special Issue published 16 articles on this topic. The issues evaluated in these papers varied from research on pregnancy outcomes to screening and diagnosis of GDM, use of new biomarkers, and evaluation of long-term metabolic risk and intervention strategies postpartum in mothers and offspring.

This Special Issue includes various important findings. For example, Zawiejska et al. show that in high-risk women, early screening for GDM using the IADPSG criteria may be a useful predictor of congenital anomalies [2]. Another study showed that inadequate gestational weight gain was very common in a large cohort of GDM with a lower risk for adverse pregnancy outcomes in women with insufficient gestational weight gain [3]. Another study demonstrated that third-trimester fetal anthropometric parameters such as fetal weight centile can be used to predict adverse neonatal outcomes beyond the classical maternal risk factors [4]. The ELENA study showed that multidisciplinary group education might help to better manage the increasing workload and is also positively evaluated by women with GDM [5].

There has long been controversy on how to screen and diagnose GDM. Bogdanet et al. provide an extensive narrative review on the several factors that can influence the results of an oral glucose tolerance test (OGTT) in pregnancy and negatively impact patient care [6]. Another review discusses emerging biomarkers to simplify screening for GDM without the need for an OGTT [7]. Raets, L. et al. reviewed the current evidence and controversies on screening for GDM in early pregnancy [8]. Another important evidence gap is how to screen and diagnose GDM in pregnant women with a history of bariatric surgery. Deleus, E. et al. reviewed the challenges of using an OGTT in pregnancy after bariatric surgery and discussed potential alternatives to screen for GDM in this high-risk population. In addition, the evidence on the association between hypoglycemia and glycemic variability with adverse pregnancy outcomes in this population was reviewed [9]. A large retrospective French study evaluated different screening strategies for hyperglycemia in pregnancy to limit the number of OGTTs during pandemics [10]. Egan, A.M. et al. from the Mayo Clinic provided an extensive narrative review on the recurrence of GDM in a second pregnancy and presented the experience from their center [11].

Deischinger, C. et al. evaluated secretagogin (SCGN) in pregnancy, which is a calciumbinding protein related to insulin release in the pancreas. They showed that SCGN is related to insulin secretion but is unrelated to the diagnosis of GDM [12]. The study design and rationale were presented of the PROMIS study, a Dutch multi-center longitudinal study 
to evaluate insulin sensitivity and glucose metabolism in overweight pregnant women and the impact on pregnancy outcomes, including early growth of the offspring [13]. In addition, a population-based study evaluated the evolution in the prevalence of diabetes among twin pregnancies and pregnancy complications in Catalonia [14].

Long-term follow-up after pregnancy with GDM is important to timely prevent metabolic complications in mothers and offspring. The study protocol of the Melinda trial was presented. This is an ongoing RCT comparing a telephone- and mobile-based lifestyle intervention with standard of care in women with prediabetes after GDM [15]. Two-year follow-up data of offspring of the San Carlos GDM Prevention Study showed that a Mediterranean diet during pregnancy was associated with a reduction in hospitalizations with antibiotic and corticosteroid treatment, and fewer hospitalizations due to asthma/bronchiolitis [16]. A review with extensive scope on the long-term metabolic risk in the offspring showed that the prevalence of overweight/obesity and glucose disorders is higher in offspring exposed to GDM compared to unexposed offspring. Importantly, overall, this association remained significant after correction for maternal overweight [17].

Conflicts of Interest: The author declares no conflict of interest.

\section{References}

1. McIntyre, H.D.; Catalano, P.; Zhang, C.; Desoye, G.; Mathiesen, E.R.; Damm, P. Gestational diabetes mellitus. Nat. Rev. Dis. Primers 2019, 5, 47. [CrossRef] [PubMed]

2. Zawiejska, A.; Wroblewska-Seniuk, K.; Gutaj, P.; Mantaj, U.; Gomulska, A.; Kippen, J.; Wender-Ozegowska, E. Early Screening for Gestational Diabetes Using IADPSG Criteria May Be a Useful Predictor for Congenital Anomalies: Preliminary Data from a High-Risk Population. J. Clin. Med. 2020, 9, 3553. [CrossRef] [PubMed]

3. Xie, X.; Liu, J.; Pujol, I.; Lopez, A.; Martinez, M.J.; Garcia-Patterson, A.; Adelantado, J.M.; Ginovart, G.; Corcoy, R. Inadequate Weight Gain According to the Institute of Medicine 2009 Guidelines in Women with Gestational Diabetes: Frequency, Clinical Predictors, and the Association with Pregnancy Outcomes. J. Clin. Med. 2020, 9, 3343. [CrossRef] [PubMed]

4. Antoniou, M.C.; Gilbert, L.; Gross, J.; Rossel, J.B.; Fumeaux, C.J.F.; Vial, Y.; Puder, J.J. Main Fetal Predictors of Adverse Neonatal Outcomes in Pregnancies with Gestational Diabetes Mellitus. J. Clin. Med. 2020, 9, 2409. [CrossRef] [PubMed]

5. Minschart, C.; Amuli, K.; Delameillieure, A.; Calewaert, P.; Mathieu, C.; Benhalima, K. Multidisciplinary Group Education for Gestational Diabetes Mellitus: A Prospective Observational Cohort Study. J. Clin. Med. 2020, 9, 509. [CrossRef] [PubMed]

6. Bogdanet, D.; O'Shea, P.; Lyons, C.; Shafat, A.; Dunne, F. The Oral Glucose Tolerance Test-Is It Time for a Change?-A Literature Review with an Emphasis on Pregnancy. J. Clin. Med. 2020, 9, 3451. [CrossRef] [PubMed]

7. Bogdanet, D.; Reddin, C.; Murphy, D.; Doheny, H.C.; Halperin, J.A.; Dunne, F.; O'Shea, P.M. Emerging Protein Biomarkers for the Diagnosis or Prediction of Gestational Diabetes_A Scoping Review. J. Clin. Med. 2021, 10, 1533. [CrossRef]

8. Raets, L.; Beunen, K.; Benhalima, K. Screening for Gestational Diabetes Mellitus in Early Pregnancy: What Is the Evidence? J. Clin. Med. 2021, 10, 1257. [CrossRef]

9. Deleus, E.; van der Schueren, B.; Devlieger, R.; Lannoo, M.; Benhalima, K. Glucose Homeostasis, Fetal Growth and Gestational Diabetes Mellitus in Pregnancy after Bariatric Surgery: A Scoping Review. J. Clin. Med. 2020, 9, 2732. [CrossRef] [PubMed]

10. Nachtergaele, C.; Vicaut, E.; Tatulashvili, S.; Pinto, S.; Bihan, H.; Sal, M.; Berkane, N.; Allard, L.; Baudry, C.; Portal, J.J.; et al. Limiting the Use of Oral Glucose Tolerance Tests to Screen for Hyperglycemia in Pregnancy during Pandemics. J. Clin. Med. 2021, 10, 397. [CrossRef]

11. Egan, A.M.; Enninga, E.A.L.; Alrahmani, L.; Weaver, A.L.; Sarras, M.P.; Ruano, R. Recurrent Gestational Diabetes Mellitus: A Narrative Review and Single-Center Experience. J. Clin. Med. 2021, 10, 569. [CrossRef]

12. Deischinger, C.; Harreiter, J.; Leitner, K.; Bancher-Todesca, D.; Baumgartner-Parzer, S.; Kautzky-Willer, A. Secretagogin is Related to Insulin Secretion but Unrelated to Gestational Diabetes Mellitus Status in Pregnancy. J. Clin. Med. 2020, 9, 2277. [CrossRef] [PubMed]

13. Kdekian, A.; Sietzema, M.; Scherjon, S.A.; Lutgers, H.; van der Beek, E.M. Pregnancy Outcomes and Maternal Insulin Sensitivity: Design and Rationale of a Multi-Center Longitudinal Study in Mother and Offspring (PROMIS). J. Clin. Med. 2021, 10, 976. [CrossRef]

14. Gortazar, L.; Flores-Le Roux, J.A.; Benaiges, D.; Sarsanedas, E.; Navarro, H.; Paya, A.; Mane, L.; Pedro-Botet, J.; Goday, A. Trends in Prevalence of Diabetes among Twin Pregnancies and Perinatal Outcomes in Catalonia between 2006 and 2015 : The DIAGESTCAT Study. J. Clin. Med. 2021, 10, 1937. [CrossRef]

15. Minschart, C.; Maes, T.; De Block, C.; Van Pottelbergh, I.; Myngheer, N.; Abrams, P.; Vinck, W.; Leuridan, L.; Mathieu, C.; Billen, J.; et al. Mobile-Based Lifestyle Intervention in Women with Glucose Intolerance after Gestational Diabetes Mellitus (MELINDA), A Multicenter Randomized Controlled Trial: Methodology and Design. J. Clin. Med. 2020, 9, 2635. [CrossRef] [PubMed] 
16. Melero, V.; Assaf-Balut, C.; Torre, N.G.; Jimenez, I.; Bordiu, E.; Valle, L.D.; Valerio, J.; Familiar, C.; Duran, A.; Runkle, I.; et al. Benefits of Adhering to a Mediterranean Diet Supplemented with Extra Virgin Olive Oil and Pistachios in Pregnancy on the Health of Offspring at 2 Years of Age. Results of the San Carlos Gestational Diabetes Mellitus Prevention Study. J. Clin. Med. 2020, 9, 1454. [CrossRef] [PubMed]

17. Nijs, H.; Benhalima, K. Gestational Diabetes Mellitus and the Long-Term Risk for Glucose Intolerance and Overweight in the Offspring: A Narrative Review. J. Clin. Med. 2020, 9, 599. [CrossRef] [PubMed] 